\title{
Travessias discursivas: intertextualidade e interdisciplinaridade no romance Netto perde sua alma, de Tabajara Ruas
}

\author{
Discursive crossings: intertextuality and interdisciplinarity in the novel \\ Netto perde sua alma, from Tabajara Ruas
}

\section{Travesías discursivas: intertextualidad e interdisciplinaridad en la novela Netto perde sua alma, de Tabajara Ruas}

\author{
${ }^{1}$ Marcelo de Andrade Duarte \\ 1'marcelo.duarte.002@acad.pucrs.br, Pontifícia Universidade Católica do Rio Grande do Sul
}

\begin{abstract}
Resumo
A partir de uma leitura crítica das relações intertextuais promovidas por Netto perde sua alma pretende-se analisar o romance, de Tabajara Ruas, não só em seu diálogo interdisciplinar com a historiografia, mas também nas relações que a obra suscita com outros textos literários. Nesse caminho, percebe-se que a historiografia tradicionalmente trata os homens que participaram de guerras como semideuses, configurando-os apenas por suas ações e participações heroicas em conflitos políticos. Enquanto o romance Netto perde sua alma, sem deixar de incorporar ações heroicas de seu protagonista, privilegia a configuração de uma dimensão humana e humanizadora de sua personagem histórica, pois a faz refletir e questionar profundamente sobre tais ações. Dessa forma, destacamos nessa leitura o processo de humanização que o romance de Tabajara Ruas promove de um personagem relevante da história do Rio Grande do Sul, o General Antonio de Souza Netto.
\end{abstract}

Palavras-Chave: Netto perde sua alma, Literatura e História, Romance Histórico, Novo Romance Histórico, Metaficção Historiográfica.

\begin{abstract}
From a critical reading of intertextual relations promoted by Netto perde sua alma is intended to analyze the novel of Tabajara Ruas, not only in its interdisciplinary dialogue with historiography, but also in the relations that the work raises with other literary texts. In this way, it is clear that historiography traditionally treats men who participated in wars as demigods, setting them just for their actions and heroic participation in political conflicts. While the novel Netto perde sua alma, while incorporating heroic actions of his protagonist, favors setting up a human and humanizing dimension of its historical character , as does the question and reflect deeply on such actions. Thus, we emphasize that reading the process of humanization that the Tabajara Ruas novel promotes an important character in the history of Rio Grande do Sul, General Antonio de Souza Netto.
\end{abstract}

Keywords: Netto perde sua alma, Literatura and History, Historic Novel, New Historic Novel, Historiographic Metafiction.

\section{Resumen}

A partir de una lectura crítica de las relaciones intertextuales promovidas por Netto perde sua alma se pretende analizar la novela de Tabajara Ruas, no sólo en su diálogo interdisciplinario con la historiografía, sino también en las relaciones que la obra plantea con otros textos literarios. De esta manera, se percibe que la historiografía trata tradicionalmente los hombres que participaron en las guerras como semidioses, estableciéndolos sólo por sus acciones y participaciones heroicas en conflictos políticos. Mientras que la novela Netto perde sua alma, sin dejar de incorporar acciones heroicas de su protagonista, favorece la configuración de una dimensión humana y humanizadora de su personaje histórico, pues lo hace reflexionar profundamente sobre este tipo de acciones. Por lo tanto, hacemos hincapié en nuestra lectura el proceso de humanización que la novela de Tabajara Ruas promueve de un personaje importante en la historia de Rio Grande do Sul, el general Antonio de Souza Netto. 
Palabras claves: Netto perde sua alma, Literatura e Historia, Novela Histórica, Nueva Novela Histórica, Metaficción Historiográfica.

O Rio Grande do Sul tem seu passado marcado por frequentes e longas guerras que começaram no século XVIII com o desmantelamento das missões jesuíticas, passando pela Guerra da Cisplatina (1825-1828), a Guerra dos Farrapos (1835-1845) e a Guerra do Paraguai (1864-1870). Tais guerras não marcaram apenas as páginas da história, mas também as dos livros da literatura gaúcha.

$\mathrm{Na}$ história da literatura gaúcha encontramos diversos romances que tratam sobre o passado militar, cada um com opiniões diferentes sobre as guerras aqui ocorridas. Muitos autores tratam as guerras como algo que não foi justo, algo que foi em vão e que o povo gaúcho apenas sofreu e jamais conquistou o devido reconhecimento nos outros Estados do Brasil. Por exemplo, em a Divina Pastora (1847) (primeiro romance gaúcho) e O Corsário (1849), ambos de Caldre e Fião, os farroupilhas são mostrados como bandidos; Já em Os Farrapos (1877), de Oliveira Belo, em sua frase final demonstra o sentimento de as revoluções terem sido injustas: "Para nada, patrício! Imolação antes do tempo! muito heroísmo semeado no rochedo!" (OLIVEIRA BELO apud SEBEN, 2005, p. 10).

As revoluções são tratadas como um acontecimento em vão por diversos autores, porém existem outros que as veem como um ato de bravura em que seus heróis foram derrotados militarmente, caso de A região submersa (1981) de Tabajara Ruas. Esse mesmo autor em Netto perde sua alma (1995), apesar de inspirar-se no contexto das revoluções, focaliza sobre outro ângulo as guerras e a atuação das personagens nelas, tratando as ações das revoluções como algo secundário, dando ênfase a uma reflexão sobre elas.

Em Netto perde sua alma, o autor insere em sua narrativa o personagem histórico General Antônio de Souza Netto como protagonista e recorre a uma fase da vida do General não documentada pela história. $\mathrm{O}$ autor coloca o personagem Netto em um ambiente de hospital, em que à beira da morte começa a refletir sobre tudo que aconteceu durante as guerras que ele vivenciou. Essa é uma fase que pouco a historiografia tratou do General, afinal a narrativa histórica revela apenas que Netto morreu no Hospital de Corrientes na Argentina, mas sobre o tempo que ele passou neste hospital não há documentos que tratem a respeito.

A narrativa de Netto perde sua alma é baseada na história do General Netto, mas como o próprio autor afirma, em um dos paratextos editoriais do romance, sua epígrafe, que tem uma intenção diferente da historiografia, pois revela o romance como uma ficção 
Deixei a aproximação com Netto acontecer da única maneira que saberia fazê-lo: com a imaginação. (...) Este romance não é, portanto, a história de Antônio de Souza Netto. É uma ficção a seu respeito, uma invenção, um sonho - meu, e de outros homens.

Netto Perde sua Alma é um romance que tem como personagem protagonista, como já foi dito, o General Antonio de Souza Netto, líder militar e político, que foi um dos principais nomes da história do Rio Grande do Sul. A historiografia aponta que Netto liderou seu próprio exército, este composto por civis que aderiram à causa de Netto e também pelo Corpo de Lanceiros Negros, formado por escravos que lutavam pela liberdade. Aponta ainda que ele lutou em diversas batalhas importantes tanto para a história do Rio Grande do Sul quanto para a história do Brasil. Entre essas batalhas temos a Revolução Farroupilha (em que situa-se grande parte da narrativa ficcional das lembranças do General), onde na Batalha do Seival, após vencer o exército imperialista, mesmo estando em desvantagem em número de soldados, Netto proclamou a República Rio-Grandense. Mas apesar de tamanha importância para a história, o General é pouco conhecido historicamente, pois os livros que tratam sobre a história tanto do Brasil quanto do Rio Grande do Sul trazem muito poucas informações a seu respeito. Os livros de história dão mais ênfase ao General Bento Gonçalves e a Giuseppe Garibaldi e tratam Netto como alguém que apenas lutou ao lado destes.

Carlos Mata Indurain (1995) reflete acerca da dificuldade que um autor de romance histórico tem para construir um personagem histórico afirmando que "Una posible solución para que los personajes resulten interesantes y creíbles, sin necesidad de modernizar su psicología, consiste en enfrentarlos con problemas eternos, como el amor, la ambición o la envidia." Tabajara Ruas, considerando a reflexão de Mata Indurain, aponta outro problema do homem que é o da morte e outros associados a ela, pois coloca o General em seus últimos momentos de vida, em um quarto de um hospital militar em Corrientes na Argentina. Nesse quarto Netto relembra os momentos mais marcantes de sua vida. Entre eles, a proclamação da república rio-grandense, que, apesar de não estar explicitada no livro, percebemos pela data, apresentada sempre antes de iniciar um novo capítulo, e sua relação com o Corpo de Lanceiros Negros, destacando-se dessa relação a amizade com Sargento Caldeira que sempre lutou ao seu lado e o encontro com Milonga, personagem marcante na vida do general.

O romance de Ruas, analisado em sua temporalidade, caracteriza-se como retrospectiva, pois o início da narrativa, o prólogo, é, na verdade, o final da história. Assim percebe-se que o que é narrado na última parte do livro a respeito da fuga do hospital com o sargento Caldeira até a chegada ao rio que o general haveria de fazer e que essa era uma 
travessia que como o próprio Netto diz "Essa travessia a gente deve fazer sozinho mesmo." Foi uma trajetória percorrida apenas pela alma de Netto e não pelo corpo já que este se encontrava na cama do hospital. Essa então, a meu ver, é a perda da alma de Netto que o autor nos propõe no título.

Ainda acerca desse prólogo, a enfermeira Zubiaurre ao entrar no quarto "Volta-se para o general brasileiro (...) coloca o espelho sob suas narinas. O General Netto também não respira mais." (RUAS, 2006, p. 10). O tempo da diegese começa na madrugada anterior à visita da enfermeira e vai retornando para contar os fatos mais marcantes da vida de Netto. Mas este retorno não é feito de maneira cronológica, pois faz saltos de um passado mais próximo a um passado mais distante e também avanços ao futuro dentro do próprio passado.

Isso tudo é conduzido por um narrador onisciente que em terceira pessoa faz fluir a narrativa, porém também dá voz às personagens.

Por algum efeito da luz ou da febre, o sargento Caldeira pareceu-lhe transparente.

-Dormindo, general?

(...)

-Vosmecê por aqui, sargento? Como le vai?

-Levando a vida no más, general.

-Como entrou a esta hora, sargento?

-Eu tenho o passo leve (RUAS, 2006, p. 35).

O narrador recorre a uma ambientação que presa muito pelo descritivismo, de modo que se pode facilmente visualizar o espaço onde está sendo narrado, conduzindo o leitor a sentir-se realmente assistindo as cenas, como podemos perceber no fragmento a seguir:

Há uma porta batendo em algum lugar. A cama da direita está vazia. A cama da esquerda tem o corpo enorme do major Ramírez, respirando pesadamente, fazendo gestos confusos. Há um reflexo de água brilhando no teto do quarto. Quando o trouxeram para o hospital, Netto viu o pequeno jardim com a fonte. Deve ser o reflexo do tanque onde está a fonte, um ser híbrido de peixe e homem com um arpão, cuspindo um jato de água. Mas o mais provável é que sejam reflexos das poças de água. Choveu toda a noite, monotonamente, uma chuva parelha e adormecedora, varada pela brisa que agitava os mosquiteiros e fazia essa porta bater em algum lugar (RUAS, 2006, p. 17).

Nesta obra o autor faz vir à tona não o General militar como um herói, mas sim o homem que existe neste herói. As guerras históricas e sua participação são razões para uma reflexão de sua própria vida. E para fazer essa reflexão o personagem dialoga com um possível fantasma, seu companheiro Sargento Caldeira, que sempre o acompanhou nas batalhas, ou apenas fruto de seu delírio proveniente da febre. Não só essa dimensão humana do general, que a história não trata, mas também do enfoque pós-guerra. Ao que se refere 
desse aspecto, a obra fala das injustiças cometidas com os negros que foram os maiores derrotados da Revolução Farroupilha, porque mesmo após assinado o tratado de paz eles não deixaram de ser escravos. Considero que a perda da alma de Netto, a que o título do romance se refere, se dá pela impossibilidade do General de ajudar e dar a liberdade prometida aos negros que lutaram ao seu lado. Pois após assinado o acordo de paz, momento em que foi extinta a República que ele havia fundado, o general se vê impossibilitado e sem poder para cumprir suas promessas. No entanto, cabe ressaltar que esse general humanizado aparece apenas nos capítulos que abrem e encerram o romance, visto que nos demais o enfoque se dá sobre as guerras, sob um viés não problematizador acerca delas.

Tabajara Ruas utiliza no decorrer de sua narrativa A Divina Comédia como um livro que Netto ganha de presente do General Osório "Netto apanhou o volume. A Divina Comédia de Dante Alighieri. Sorriu.” (RUAS, 2006, p. 100) e diz que irá acompanhá-lo em suas noites de inverno. A intertextualidade com a obra de Dante não se dá apenas como uma citação e está presente também pela imagem do barqueiro Caronte, que conduz as almas ao inferno e por outras passagens que colocam Netto possivelmente na porta do inferno. A imagem do Sargento Caldeira que aparece nos momentos finais pode-se dizer que é o cumprimento de uma promessa do próprio que diz a Netto na seguinte passagem que: "Se vosmecê fundar um país, coronel, eu o acompanho até a porta do Inferno.” (RUAS, 2006, p. 87). Assim, uma possível hipótese de leitura é que o sargento retorne para levar Netto até a porta do inferno então, pois em A Divina Comédia no início do Canto III temos o seguinte:

\footnotetext{
Chegando à porta do inferno, os dois poetas deparam a ameaçadora inscrição. Entram e encontram no vestíbulo o caminho; alcançam Aqueronte, rio onde Caronte, o barqueiro infernal, conduz as almas dos danados á margem oposta, rumo ao suplício (ALIGHIERI, 2004, p. 18-19).
}

Caronte é quem conduz as almas da porta até o inferno, e essa imagem do barqueiro está presente quando o sargento Caldeira leva o general Netto até uma margem onde já estava à espera de tal canoeiro, então do interior da neblina aparece o perfil de uma canoa, conduzida por um homem coberto por uma capa negra que parou a alguns metros do general. Netto pergunta para o sargento para onde levaria esta canoa, esse o responde dizendo que seria para a outra margem, possivelmente a travessia da porta para a margem do suplício citada anteriormente da obra de Dante, mas também diz ao general que essa passagem ele já havia feito na batalha de Tuyuty e que Netto deveria fazê-la sozinho.

Mesmo tendo sido um herói de guerra, o general teve de derramar o sangue de muita gente e ele mesmo reflete sobre isso, na passagem que virá logo abaixo, talvez por isso ele 
acabe indo para este inferno, que segundo Dante não é só para as pessoas que foram ruins, mas também para as que tiveram vida virtuosa mesmo indo contra algumas leis de Deus.

- Eu matei índios. Matei negros. E matei brancos. Mais do que tudo, matei castelhanos: uruguaios, argentinos, paraguaios, chilenos. (...) Aqui neste quarto ficava matutando comigo mesmo nessa gente toda que matei e me dava um peso enorme no coração, sargento. (...) A gente quer se lembrar por que matou tanto, (...) e não acha reposta que valha a pena tanto sangue. Não me lembro mais das palavras, só me lembro dos mortos, um a um (RUAS, 2006, p. 143).

Através dessa rede intertextual entre A Divina Comédia, bem como a relação possível com o romance de Gabriel García Marquez, O General em seu Labirinto (1989), através da proposta narrativa sobre o final da vida de um general, e a historiografia percebemos que mesmo pelos textos historiográficos fazerem parte desta obra, Netto perde sua alma, em partes, vai além apresentando um General desconhecido até então que apenas era configurado por suas participações nas guerras, em um aspecto heroico que não considerava sua dimensão humana. Essa ficcionalização da história que a literatura nos oferece reconstrói o cenário histórico da Revolução Farroupilha e de um personagem importante durante ela, gerando assim uma reflexão em relação aos episódios e as personagens heroicamente mitificadas para o povo através da historiografia.

Ao realizarmos uma breve pesquisa da fortuna crítica de Netto perde sua alma, percebemos que a crítica coloca tal obra como pertencente ao gênero romance histórico, cuja origem se dá no texto "O Romance Histórico", de Lukács (escrito durante seu exílio na Rússia), primeira reflexão teórica moderna acerca da relação entre literatura e história (desde o parágrafo 50 da Poética, de Aristóteles, não se pensava, teoricamente, essa questão). Nessa obra, Lukács define o modelo conceitual para descrever e refletir a representação da realidade histórica realizada pela literatura.

Em consonância ao que foi exposto anteriormente (principalmente quando tratamos de Bakhtin), Lukács afirma que a relação entre literatura e história se dá essencialmente no romance, por ser o romance um gênero híbrido. Podemos também perceber a influência de Bakhtin, pois Lukács tinha por método estudar a literatura pelo que está fora do texto, as relações sócio históricas.

Ao propor a especificidade do romance histórico, Lukács afirma que todo romance histórico precisa de um tema histórico, porém para ser um romance histórico o que importa é a história como representação ou figuração, ou seja, é necessário que o escritor se volte para o passado com uma visão calcada no presente. Esse romance histórico decorre de uma nova consciência que transforma a história em uma experiência do povo, em que o povo sinta-se 
como parte integrante da mesma, diferente do que ocorria na epopeia, em que era impossível a população visualizar-se naquela história, devido à distância épica.

Lukács define o momento das revoluções (sobretudo a Francesa) como preponderante para o surgimento do romance histórico, pois antes o homem não se sentia pertencente à história, já que a história elevava os deuses e reis, não considerando as massas. Quando as massas passam a fazer parte da história, o passado deixa de ser distante, e começa a ser importante, pois explica o presente.

Através do sentimento de pertencimento à história, os sujeitos reconhecem sua importância para a construção desse presente. Tais sujeitos reconhecem sua existência como algo historicamente construído e passam a ver no passado algo que determina sua existência cotidiana, dizendo-lhes respeito diretamente.

Para pensar tais questões na literatura, Lukács refere-se especificamente a Walter Scott (Edimburgo, Escócia, 1814-1819) que em suas obras, primeiramente Waverley (1814), depois Ivanhoé (1819), expôs alguns importantes acontecimentos da história do Reino Unido, e que o filósofo húngaro define como o criador de um gênero híbrido de história e ficção (em pleno romantismo europeu), o romance histórico. Ao analisar as obras de Walter Scott, Lukács define que no romance histórico clássico o passado histórico é representado de forma a anular a intervenção do tempo da enunciação sobre o tempo da diegese, ou seja, não se pode "reconstruir" a história, mas sim tentar descrever o passado tal qual ele ocorreu. Sendo assim, volta-se ao passado para afirmar e confirmar valores do presente, pois havia uma consciência histórica que considerava um passado (retratando os grandes eventos da história) onde encontraríamos relevância para o presente.

Na tentativa de reconstrução do passado como ocorreu, Walter Scott mesclava fatos com ficção, acrescentando personagens fictícios que não participaram da história. Como protagonista do romance histórico, Scott colocava um herói mediano, ou seja, um tipo social que representava uma coletividade, um homem comum (que terá papel relativamente decisivo no passado histórico) em que todos pudessem se reconhecer, para, assim, não utilizar personagens históricos para a construção do romance.

Scott não utilizava os grandes sujeitos da história, já que, ao utilizar um personagem histórico, seria necessário ficcionalizá-lo, sendo assim, não teríamos mais um espelho do passado, mas sim uma refiguração do mesmo. Dessa maneira, as grandes personalidades da história aparecem como pano de fundo da narrativa, assim como os grandes acontecimentos históricos oficiais, pois também seria impossível reconstruí-los tais como ocorreram. 
Quanto à concepção ideológica do romance histórico, nota-se que ele prende-se ao ideal de história hegemônica que compreende ao "positivismo histórico" em que o historiador, tendo acesso às fontes primárias, seria capaz de reconstituir qualquer momento histórico (esse positivismo histórico é claramente identificado nos romances de Walter Scott). Já quanto à forma, notamos que o romance histórico proposto por Lukács, aproxima-se de uma das características da épica, conforme análise de Bakhtin, onde há um passado absoluto, em que Scott coloca a história ao fundo, como cenário, tendo um grande cuidado para não alterá-la.

Dentro do que foi teorizado pelo filósofo húngaro, devemos discordar do que é defendido pela fortuna crítica do romance de Ruas, já que segundo Lukács no romance histórico não podemos ter personagens históricos como protagonistas, sim pessoas comuns para que o povo sinta-se pertencente à história. Ao colocar um personagem histórico como protagonista, o romance está de certa forma modificando a história, ou seja, mesmo com temática histórica, poucos serão romances históricos, pois seriam apenas aqueles em que o passado interfere sobre o presente e não os que andam no caminho contrário, ou seja, romances que repensem a história, não poderiam se inserir no conceito de Lukács.

Diante dessa impossibilidade de determinados romances serem históricos, Seymour Menton, propõe o conceito de novo romance histórico, vinculado a um "novo" paradigma de representação do passado, decorrente de um corpus literário específico, essencialmente, da América Latina (a partir de 1949, já que Menton considera O Reino deste Mundo, de Alejo Carpentier, como o primeiro novo romance histórico). Tal conceito proposto por Menton, pela própria terminologia, percebe-se que é vinculado à tradição teórica do romance histórico de Lukács, porém o autor em nenhum momento propõe uma revisão desse conceito, o que, como citamos anteriormente, é necessário nas pesquisas, principalmente, das Ciências Humanas. Lukasz Grützmacher, estudioso da Universidade de Varsóvia criticou o fato de Menton apenas enfatizar o novo, sem recuperar o conceito de Lukács.

Como diferencial do que foi teorizado por Lukács, Menton afirma que no novo romance histórico existe uma problematização da história, em oposição ao positivismo histórico, que Lukács estudou a partir dos romances de Walter Scott. Contudo na proposição do "novo" Menton refere-se a conceitos já tratados por Lukács, já que no novo romance histórico teríamos a história não como tema, mas como uma representação "que traz o passado para perto de nós e o torna experenciável” (LUKÁCS, 2011, p. 73). Percebe-se que Menton fez uma leitura equivocada da teoria de Lukács, pois ele confunde uma das modalidades do romance histórico com todo o conceito de romance histórico. 
Menton enumera seis características dos novos romances históricos, no entanto entre elas existem algumas que se assemelham ao que foi postulado por Lukács, entre elas destacamos a intertextualidade e o dialogismo, pois no momento em que o filósofo húngaro propõe que existe uma relação entre história e literatura, ele está se valendo de tais conceitos. Assim, todo o romance histórico, mais ainda, todo o romance é intertextual e dialógico por excelência, visto que, conforme Bakhtin, o dialogismo é encontrado em qualquer discurso, não apenas no literário. Quanto a tais características do novo romance histórico que viriam a romper com o paradigma proposto por Lukács, Grützmacher afirma que são muito superficiais, causando mais confusão que esclarecimentos.

A proposta de Menton aparece muito mais com um caráter didático e histórico da literatura latino-americana, visto que carece de fundamentação teórica, porque para ele basta a questão do distanciamento entre o autor e a história narrada (cf. a definição de Anderson Imbert). Levando em consideração esse pressuposto teórico, Menton descarta alguns romances cuja diegese fosse contemporânea ao escritor, citando o exemplo do romance de Gabriel García Márquez, Cem Anos de Solidão, pois a geração mais jovem coincide com a do escritor. Todavia, entre outras confusões causadas por Menton, ao analisar as características do novo romance histórico, cita a mesma obra de García Márquez como sendo um novo romance histórico, porque tem em suas características a intertextualidade e a carnavalização.

No caso de Netto perde sua alma, poderíamos classificá-lo como um novo romance histórico levando em consideração a distância entre autor e história narrada. No entanto, creio que alguns pontos, como a carnavalização, não seja traço presente no romance de Ruas.

Quanto às estratégias narrativas utilizadas por Ruas temos uma possível metaficção que seria um empreendimento da literatura pós-moderna, pois segundo Flora Süssekind, em estudo sobre o romance Em Liberdade, de Silviano Santiago, só por realçar diversas referências históricas junto à ficcionalidade, além da mistura de gêneros, o romance de Santiago poderia ser considerado uma metaficção. Porém acredito que Tabajara não chega a esse ponto, apesar de os capítulos inicial e final serem uma paródia de como as narrativas históricas tratam os generais farroupilhas, pois grande parte de seu romance apresenta um olhar distante da história, diferente de Santiago que, ao reconstruir um período da vida de Graciliano Ramos, problematiza o discurso confessional e histórico, algo que vejo não ocorrer em no romance de Ruas.

Para elucidarmos o conceito de metaficção trazemos aqui Linda Hutcheon que, em Poética do pós-modernismo (1991), segue o raciocínio de White, para o qual a distinção entre real e ficcional torna-se problemática, pois permite que o texto histórico não mais apresente 
eventos passados, mas sim possíveis interpretações para os mesmos. Afirmamos que Linda está filiada a tal pensamento de White, pois para a mesma, a metaficção historiográfica é o empreendimento da ficção pós-moderna que parte de um fato histórico e ficcionaliza-o, buscando uma revisão do passado, apresentado pela história tradicional. A metaficção nos apresenta uma diluição das fronteiras, por exemplo, entre romance e história/romance e biografia etc.

Para uma obra ser classificada como metaficção historiográfica deve ter algumas características: autorreflexividade, referências a personagens e eventos históricos, utilização das convenções para subvertê-las, não negar a existência do passado, não por meio de um retorno nostálgico ao mesmo, mas voltando a ele (abalando suas estruturas sem destruí-las) para mantê-lo vivo sob um filtro de desconfiança e ceticismo. Sendo assim, obras consideradas metaficcionais problematizam o saber histórico e como o mesmo nos é acessível, permitindo assim não mais a "verdade absoluta" preconizada pela história, mas uma construção de verdades históricas. Percebemos que os romances latino-americanos apresentam esse caráter metaficcional, visto que buscam a reconstrução de uma história criada pelo colonizador europeu. Além da ficção latino-americana, percebemos isso também na literatura pós-colonial, por exemplo, dos países africanos, que assim como os latinoamericanos, visam contar a "sua" história, devastada pelos colonizadores.

Caracterizando a metaficção como um empreendimento pós-moderno, Linda nos conduz a um pensamento: história e ficção estão condicionados historicamente. Quer dizer, cada contexto histórico solicita uma determinada narrativa, por exemplo, o romance histórico, iniciado por Walter Scott, dava conta das representações daquele momento, porém não seria possível nos dias de hoje. A metaficção seria, então, para o pós-modernismo o que o romance histórico era para os tempos de Scott. O pós-modernismo, para Linda é "um processo ou atividade cultural em andamento, e creio que precisamos [...] de uma poética [...] em constante mutação, com a qual possamos organizar nosso conhecimento cultural e nossos procedimentos críticos" (HUTCHEON, 1991, p. 31-32).

Ao refletirmos sobre o prefixo "pós" percebemos que o mesmo indica uma continuidade e ao mesmo tempo uma ruptura com o passado - o modernismo, ou seja, conforme Hutcheon, não é um simples e radical rompimento nem uma continuação do modernismo, mas "ele tem esses dois aspectos e, ao mesmo tempo, não tem nenhum dos dois. E isso ocorreria em termos estéticos, filosóficos ou ideológicos." (HUTCHEON, 1991, p. 36). O pós apresenta-se como uma prática cultural que coloca o modernismo em evidência para 
poder abalar suas estruturas, através de um pensamento sem tutelas (religião e arte). O pósmodernismo questiona a cultura a partir do seu interior, sem a intenção de destruí-la.

Conforme vimos, a metaficção não tem o objetivo de conservar o passado, mas de "reinventá-lo", o que para Jameson é um problema, pois, baseado nos ideais de Lukács, desse modo não é possível experenciar o passado, e as distorções realizadas pela metaficção impedem isso. Porém tais distorções da história feitas pela metaficção são para criticar o discurso histórico que visa a construção de uma verdade absoluta. Essa verdade absoluta seria impossível, porque o texto é sempre uma representação de uma realidade, nunca um espelho, para o discurso historiográfico não seria diferente, pois, segundo White, ao filiar-se a determinada perspectiva teórica da história, os historiadores não estão fazendo uma construção discursiva neutra, sim altamente ideológica, como o são todos os discursos (cf. pressupostos de Bakhtin). Jameson afirma que o que a metaficção faz nada mais que citações do passado, que em nada problematizariam o mesmo, apenas o utilizaria como pano de fundo narrativo.

Ao traçar um paralelo entre o romance histórico e a metaficção, Hutcheon afirma que o romance histórico, conforme foi definido por Lukács, seria capaz de "encenar o processo histórico por meio da apresentação de um microcosmo que generaliza e concentra" (LUKÁCS apud HUTCHEON, 1991, p. 151). Pensando o romance histórico dessa maneira, em muito pouco ele se difere da narrativa historiográfica, que também busca um espelho da realidade, salvo que o personagem protagonista não pode ser uma personalidade histórica, por medo de alterar-se o passado. O que difere-se muito da metaficção que busca justamente essa alteração do passado, para abalar suas estruturas.

Outras diferenças podem ser percebidas entre o romance histórico e a metaficção podem ser percebidas. Em primeiro lugar, o romance histórico busca a reconstrução de uma verdade histórica, já a metaficção apropria-se dessas verdades, falsificando-as para criticando as falhas que a memória da história pode oferecer, falhas propositais ou não. Segundo, o romance histórico assimila os dados históricos visando proporcionar uma sensação de "verdade" ao mundo ficcional; a metaficção incorpora os dados históricos, mas não os assimila, podendo enfatizar, como uma crítica, o processo de tentar assimilar tais dados. Por fim, os personagens históricos aparecem na narrativa do romance histórico como uma forma de "legitimizar ou autenticar o mundo ficcional com sua presença, como se para ocultar as ligações entre ficção e história com um passe de mágica ontológico e formal” (HUTCHEON, 
1991, p. 152). Quanto a isso, a autorreflexividade da metaficção impede esse empreendimento.

A metaficção historiográfica é ao mesmo tempo uma obra de ficção que tem um fechamento modernista que vai subverter o formalismo para além dos limites do texto. Diferente do formalismo, a metaficção não apaga o referencial, problematizando os referentes da história, diferente de Barthes. Assim como White, Linda afirma que como nossa relação com o mundo se dá de modo textual, podemos problematizar as verdades, já que o discurso é carregado de ideologias.

Desse modo, no pensamento de Jameson o romance histórico não é possível na modernidade: "O romance histórico não deve mostrar nem existências individuais nem acontecimentos históricos: mas a intersecção de ambos." (JAMESON, p. 192). Pois tomando Ulisses, de Joyce, como o romance que inaugura a estética modernista. O que caracterizaria a estética modernista seria a "hiper" subjetividade, com isso perde-se a objetividade com relação ao passado, não sendo possível apresentar a intersecção entre individualismo e acontecimentos históricos, pois o enfoque modernista está nas subjetividades "[...] o subjetivismo intensificado do texto modernista torna cada vez mais difícil discernir a objetividade da dimensão histórica.” (JAMESON, p. 200). Ainda tomando como exemplo Ulisses, nesse romance as personagens não vivem experiências históricas a partir dos eventos que se apresentam, impossibilitando o romance histórico.

Para Mignolo, a verdade na ficção apresenta-se quando é imitado um discurso encaixado na convenção de veracidade, ou seja, a fronteira que separa História e Literatura é muito tênue, a tal ponto que em momentos chega a se diluir. Quanto a isso, Ricoeur afirmava que literatura e história são discursos diferentes que em determinados momentos entrecruzamse sem perder sua especificidade. De modo que ao lermos literatura sabemos que se trata de tal discurso, da mesma maneira ao lermos o discurso historiográfico sabemos que se trata do mesmo, e essa percepção das diferenças, conforme Mignolo, qualquer pessoa é capaz de fazer. Bem como White demonstra, História e Literatura andam lado a lado na construção discursiva tanto da história quanto da literatura, apropriando-se uma da outra para tal.

Ao analisarmos tais teorias e críticas apresentadas até aqui acerca do entrelaçamento entre os discursos literário e histórico, percebemos que se torna difícil uma tentativa de articular o texto de Tabajara Ruas a algum desses conceitos, pois estaria em parte filiado ao novo romance histórico e em parte à metaficção historiográfica. A respeito das intertextualidades estabelecidas por Netto perde sua alma, percebe-se que quanto à obra de 
Dante, ela se dá de modo claro, tanto por meio da citação do título da obra, como do personagem Caronte.

No entanto, outro texto que não está explícito e que também não é trazido pela fortuna crítica da obra de Ruas é com o romance de García Marquez, O General em seu Labirinto que relata os últimos dias do General Simón Bolívar, sua viagem de Bogotá até a costa caribenha da Colômbia, na tentativa de abandonar a América para exilar-se na Colômbia, no decorrer dessa viagem o general é apresentado à beira da morte, enfraquecido, mesmo tendo um passado tão poderoso, o romance demonstra que apesar de estar morrendo "materialmente" seu espírito (ou sua alma) ainda é forte o que o faz resistir até o fim; há também a presença de um servo fiel, José Palacios. Outro ponto a ser destacado é que o romance de García Marquez é narrado em terceira pessoa com flashbacks relativos a determinadas passagens do passado heroico de Simón Bolivar.

Percebemos nesse breve comentário da obra de García Marquez muitas proximidades com o texto de Ruas, pois também narra uma fase da vida de um general pouco documentada, ambos versam sobre a morte, os dois romances são narrados em terceira pessoa com narradores onisciente com flashbacks do passado heroico dos generais Netto e Simon Bolivar. Porém nesses flashbacks, Netto perde sua alma mostra-se com um distanciamento dos acontecimentos históricos, já a obra de García Marquez o faz com o intuito de problematizar não só o discurso histórico, mas o presente (fim dos anos 90) da América Latina e todos seus problemas ainda não enfrentados, como a tentativa de unificação das nações hispanoamericanas sob um só governo. No final dos dois romances, os generais, apesar das doenças, apresentam-se fortes, demonstrando forças para dar suas últimas ordens mesmo no leito de morte.

Creio que ao fazer tais aproximações intertextuais e interdisciplinares Netto perde sua alma apresenta uma proposta diferencial ao lançar mão, nos capítulos que abrem e encerram o romance, do onírico, através dos delírios de Netto, uma estratégia que afastaria de um relato histórico tradicional. No entanto, como já afirmamos, os referencias históricos são apresentados de modo tradicional, pois se tivesse a intenção de apresentar a quase perfeição dos momentos de guerra ali narrados como sendo também um devaneio, o que problematizaria a guerra como algo positivo, acredito que o narrador deveria ser o próprio general, não um que já detém o conhecimento da narrativa, pois nos apresenta no prólogo o general Netto morto.

\section{Referências}


ALIGHIERI, Dante. A divina comédia; tradução de Fábio M. Alberti - Porto Alegre: L\&PM, 2004.

ARISTÓTELES. Poética. Trad. Eudoro de Souza. São Paulo: Nova Cultural, 1987 [cap. IX].

BAKHTIN, Mikhail. Epos e romance. Questões de literatura e estética; a teoria do romance. Trad. Aurora Fornoni Bernardini et. al. São Paulo: Hucitec; UNESP, 1993 [pp. 397-428].

BORGES, Jorge Luis. Obras Completas. São Paulo: Globo, 1998.

CESAR, Guilhermino. História da literatura do Rio Grande do Sul. Porto Alegre: Globo, 1971.

GRÜTZMACHER, Lukasz. Las Trampas del concepto "la nueva novela histórica" y de la retórica de la historia postoficial. Acta Poética. México, D.F, v.27, n.1, pp. 141-168. 2006. Disponível em: <http://132.248.101.214/html-docs/acta-poetica/27-1/141-168.pdf>.

HUTCHEON, Linda. Poética do pós-modernismo: história, teoria, ficção. Trad. CRUZ, Ricardo. Rio de Janeiro: Imago Ed., 1991.

JAMESON, Fredric. O romance histórico ainda é possível? Trad. MADER, Hugo. Novos Estudos, n. 77 [online], março/2007, p. 185-203. Disponível em: <http://www.scielo.br/pdf/nec/n77/a09n77.pdf>. Acessado em 23/07/2013.

LUKÁCS, Gyorgy. A forma clássica do romance histórico. O romance histórico. Trad. Rubens Enderle. São Paulo: Boitempo Editorial, 2011 [pp. 33-113].

MÁRQUEZ, Gabriel García. O General em seu labirinto. Rio de Janeiro: Record, 2000.

MATA INDURÁIN, C. "Retrospectiva sobre la evolución de la novela histórica". In: SPANG, K. et al. (Ed.) La novela histórica. Teoria y comentarios. Barañain,U.N. 1995, p.13-63.

MENTON, Seymour. La nueva novela histórica de la América Latina. México: Fondo de Cultura Económica, 1992 [pp. 26-66].

MIGNOLO, Walter. Lógica das diferenças e política das semelhanças: da Literatura que parece História ou Antropologia, e vice-versa. In. CHIAPPINI, Lígia \& AGUIAR,

Flávio Wolf de. Literatura e História na América Latina. São Paulo: Edusp, 1993. p. 115135

RUAS, Tabajara. Netto perde sua alma. $4^{\circ}$ Ed. - Rio de Janeiro: Record, 2006.

SUSSEKIND, Flora. Literatura e vida literária. Rio de Janeiro: Ed. Jorge Zahar, 1985. 